NEUROLOGICAL PICTURE

\title{
Diffusion weighted MRI demonstrates abnormal pyramidal tract in hemiparesis
}

A

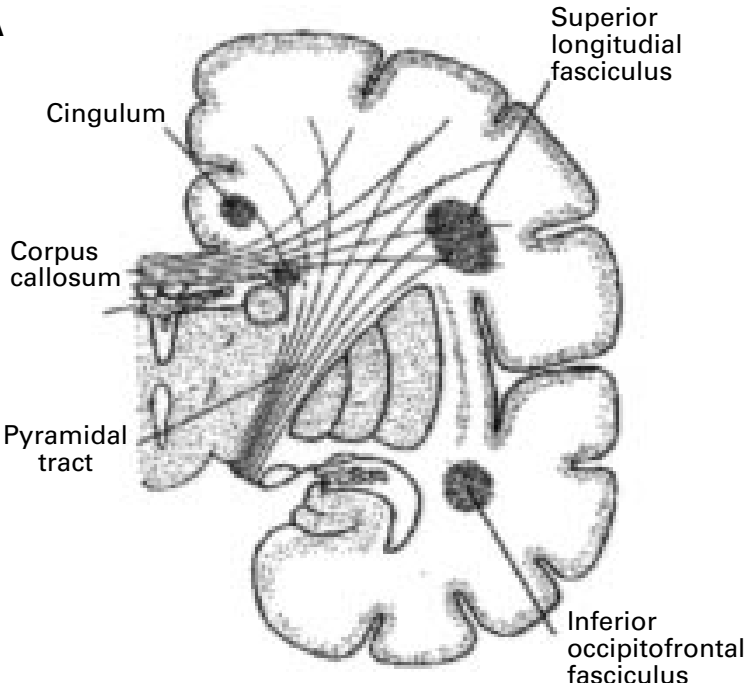

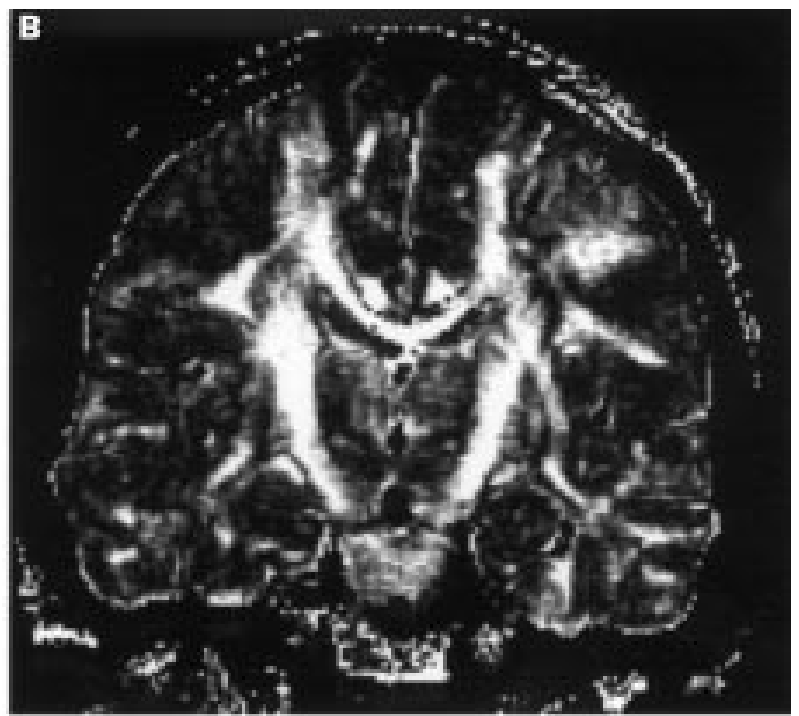

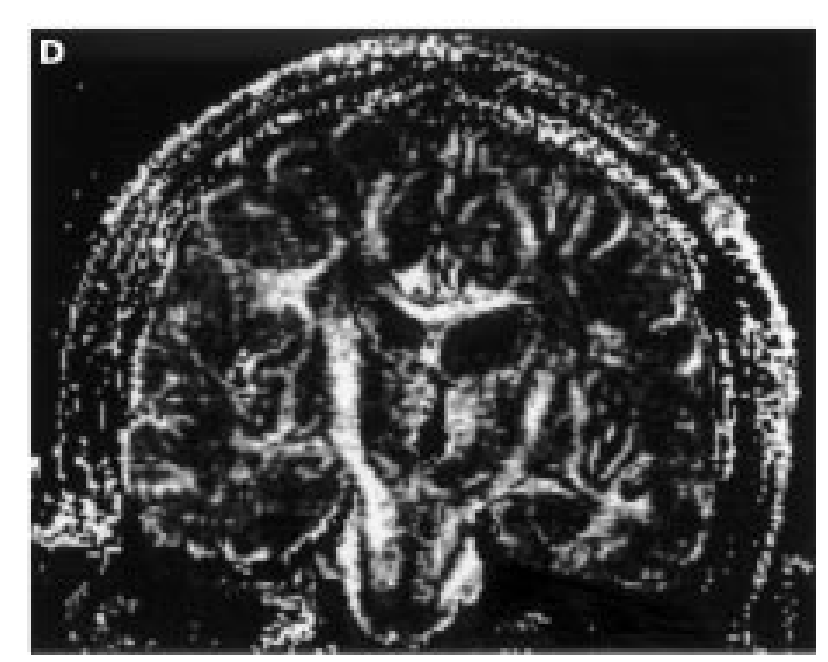

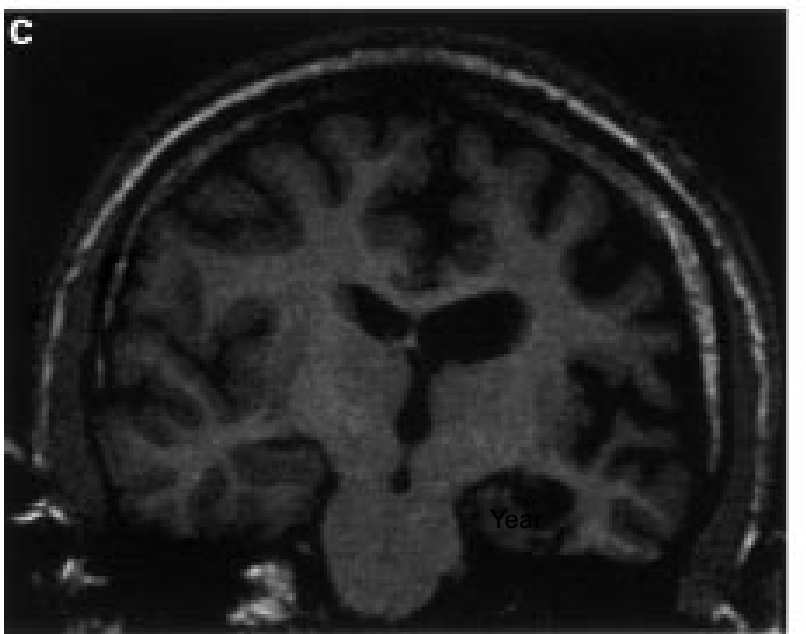

Diffusion weighted imaging (DWI) is a magnetic resonance imaging technique which is sensitive to the molecular motion of water and allows measurements of anisotropy (the directionality) of water diffusion. ${ }^{1}$ Measurements of anisotropy provides information about tracts, because water molecules travel predominantly parallel but not perpendicular to tracts. ${ }^{2}$ The anisotropy of diffusion can be calculated on a pixel by pixel basis and calculated images (maps) of anisotropy can be generated. We investigated the pyramidal tract in two patients with hemiparesis using a method to estimate anisotropy proposed by Van Gelderen et al. ${ }^{3}$ On anisotropy maps the pyramidal tract was visible and symmetric in all six investigated control subjects. In the two patients a reduction of anisotropy suggesting a disruption of the microstructural organisation of the pyramidal tract ${ }^{4}$ was detected on the clinically abnormal side on anisotropy maps. Our finding suggests that anisotropy measurements can be used as a tool to visualise abnormal tracts in vivo. (A) schematic drawing of a coronal section through the hemisphere. The pyramidal tract consists of projection fibres and forms the posterior limb of the internal capsule. (B) Anisotropy map of a normal control subject. (C) T1 weighted image of a patient with hemiparesis. (D) Anisotropy map of the same patient showing the abnormal pyramidal tract. 
This research has been kindly funded by an European Community Fellowship (UCW), by the National Society for Epilepsy (MRS and KDB), the Brain Research Trust (CAC and MRS) and the Multiple Sclerosis Society of Great Britain and Northern Ireland (GJB). We thank Dr BE Kendall and Dr JM Stevens for their helpful comments. We thank Dr JS Duncan for permission to study his patients.

UDO C WIESHMANN MARK R SYMMS

PHILIPPA A BARTLETT SIMON D SHORVON

NSE Epilepsy Research MRI Unit, Epilepsy Research Group

CHRIS A CLARK

GARETH J BARKER

NMR Research Unit, Institute of Neurology, Queen Square,

London WC1N3BG, UK

Correspondence to: Dr Udo C Wieshmann, NMR Research Unit, Institute of Neurology, Queen Square London WC1N3BG, UK. Telephone 00441494 874646; fax: 00441494 875666; email uwiesh@ion.ucl.ac.uk

1 Stejskal EO, Tanner JE. Use of spin echo pulsed magnetic field gradient to study anisotropic restricted diffusion and flow. 7 Chem Phys 1965;43:3579-603.

2 Moseley ME, Cohen Y, Kucharczyk J, et al. Diffusion weighted MR imaging of anisotropic water diffusion in cat central nervous system. Radiology 1990;176:439-45.

3 Van Gelderen P, DeVleeschouwer MH, DesPres D, et al. Water diffusion and acute stroke. Magn Reson Med 1994:31:154-63.

4 Beaulieu C, Does MD, Snyder RE, et al. Changes in water diffusion due to Wallerian degeneration in periphal nerve. Magn Reson Med 1996;36:627-31.

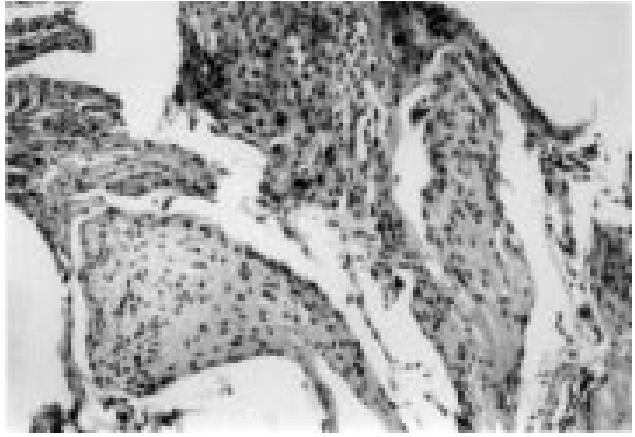

Pathological specimen showing meningothelial cells consistent wiht the diagnosis of meningioma.

(Haematoxylin and eosin originally $\times 20$.)

Cushing's strong belief on the aetiology of meningiomas. ${ }^{3}$ General Leonard Wood, Major General and Chief of Staff of the United States Army, developed a parasagittal meningioma 12 years after hitting his head on a chandelier. Cushing first examined General Wood in 1909, at a time when the diagnosis of suspected brain tumour still relied predominantly on clinical findings. After an "initial wait and see" policy, Cushing decided to perform the operation in two stages, 4 days apart. The surgery was a tremendous success and the patient was walking around his room 11 days after the procedure. This was the first time that Cushing had successfully removed a parasagittal meningioma. ${ }^{1}$ This procedure catapulted Cushing's career and he was soon promoted to Surgeon in Chief of the new Peter Bent Brigham Hospital in Boston. Additionally, it invigorated the fledgling specialty of neurosurgery and instilled a positive attitude by the public towards brain surgery and the possibility of survival from such operations.

Our case is reminiscent of the General Wood case described by Cushing. ${ }^{3}$ Our patient was fishing on a causeway when he was struck on the right frontal skull by a full beer bottle thrown from a passing car. The patient sustained a large laceration which bled profusely. At the time, he was seen by emergency room personnel and the laceration was sutured. He remained symptom free for 11 years, until the last admission. Examination of the patient disclosed a healed scar over the 11 year old laceration. The presence of disrupted bone and remoulding with hyperostosis as well as lysis of bone matrix at the point of injury supports a direct causal relation. The histological confirmation of cicatrix adjacent to tumour implicates scar formation as the oncogenic factor in meningioma formation. The leptomeningeal formation of this partially calcified meningioma and the precise correlation with the wound corroborates Cushing's original premise.

We present a case supporting Cushing's hypothesis that a causal relation exists between head trauma, resultant scar formation, and the development of meningiomas.

We thank Dr Archinto P Anzil and Dr Chandrakant Rao of the Department of Pathology for their invaluable assistance in the preparation of this manuscript. This work and the paper were funded in part by the Harry Arthur Kaplan Neurosurgical Foundation.

RENE M KOTZEN RICHARD M SWANSON THOMAS H MILHORAT

Department of Neurosurgery, State University Health Science Center at Brooklyn, King's County Hospital Center, Brooklyn, New York and The Long Island College Hospital, Brooklyn, New York, USA

JOHN A BOOCKVAR

Department of Neurosurgery, University of Pennsylvania Medical Center, Philadelphia, PA, USA

Correspondence to: Dr John A Boockvar, University of Pennsylvania, Department of Neurosurgery, 5 Silverstein Pavilion, 3400 Spruce Street, Philadelphia, PA 19104-6380, USA. Telephone 001215735 9404; email boockvar@mail.med.upenn.edu

1 Cushing H, Eisenhardt L. Meningiomas. Springfield, IL: Charles C Thomas, 1938:71-3; 409-14; 429-30; 604-13. Schiffer J, Avidan D, Rapp A. Posttraumatic meningioma. Neurosurgery 1985;17:84-7.

3 Ljunggren B. The case of General Wood. F Neurosurg 1982; 56:471-4.

4 Walshe $F$. Head injuries as a factor in the aetiology of intracranial meningioma. Lancet 1961;2:993-6. 